\title{
Experimental and Theoretical Soft X-ray Study of Nicotine and Related Compounds
}

\author{
Hanan Sa'adeh,* Frederick Backler, Feng Wang,* Susanna Piccirillo, Alessandra Ciavardini, \\ Robert Richter, Marcello Coreno, and Kevin C. Prince
}

Cite This: J. Phys. Chem. A 2020, 124, 4025-4035

Read Online

ACCESS

Џ Metrics \& More

Article Recommendations

Supporting Information

ABSTRACT: The valence and core electronic structure of nicotine, nicotinic acid, and nicotinamide have been studied by photoelectron and soft X-ray absorption spectroscopy, supported by theoretical calculations, which take into account conformational isomerism. The core-level photoionization spectra of all molecules have been assigned, and theory indicates that the effects of conformational differences are small, generally less than the natural line widths of the core ionic states. However, in the case of nicotinamide, the theoretical valence ionization potentials of cis and trans conformers differ significantly in the outer valence space, and the experimental spectrum is in

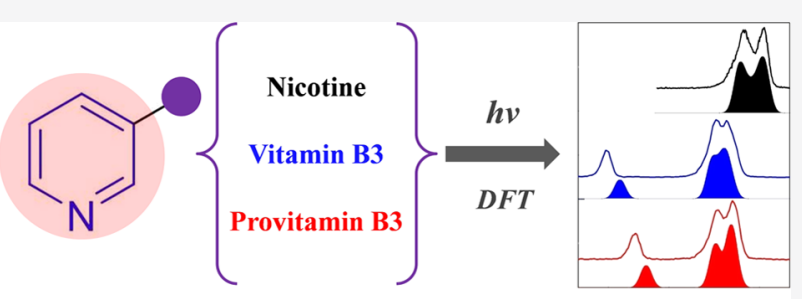
agreement with the calculated outer valence cis conformer spectrum. In addition, the $\mathrm{C}, \mathrm{N}$, and $\mathrm{O} \mathrm{K}$ edge near-edge absorption fine structure spectra are reported and interpreted by comparison with reference compounds. We find evidence at the $\mathrm{N}$ and $\mathrm{O} \mathrm{K}$ edges of interaction between the delocalized orbitals of the pyridine ring and the substituents for nicotinic acid and nicotinamide. The strength of the interaction varies because the first is planar, while the second is twisted, reducing the extent of orbital mixing.

\section{INTRODUCTION}

Nicotine, nicotinic acid (vitamin B3), and nicotinamide (provitamin B3) (Figure 1) are three derivatives of pyridine and are important bioactive chemicals: nicotine for its wellknown pharmacological and insecticidal properties, and the other two as vitamins. These three compounds differ by the substituent on the pyridine ring in the 3 position, either 1methylpyrrolidine, carboxylic acid, or carboxamide. Nicotinic acid and nicotinamide are isoelectronic, so similarities in their spectra and behavior may be expected.

The gas-phase rotational spectra of all three molecules are reported in the literature: for nicotine, several conformers are possible, but only two were observed at the temperature of the experiment of Grabow et al. ${ }^{1}$ The relative energies of the conformers of nicotine have been calculated by Elmore and Dougherty, ${ }^{2}$ and the gas-phase electron diffraction pattern has been measured by Takeshima et al. ${ }^{3}$

The rotational spectra of nicotinic acid and nicotinamide have also been measured, and the situation is relatively straightforward, as only trans and cis (or equivalently, $E$ and $Z$ ) conformers are expected to be stable. Vogelsanger et $\mathrm{al}^{4}{ }^{4}$ found that the trans form, in which the carbonyl oxygen of nicotinamide was oriented away from the pyridine nitrogen, was slightly more stable than the cis form, in qualitative agreement with their calculations. They also found that the molecules were not planar, and in both conformers, the carboxamide group was twisted out of the pyridine plane.
Mata et al. ${ }^{5}$ found that the trans form of nicotinic acid (carbonyl oxygen oriented away from the pyridine nitrogen) had about the same energy as the cis form, while calculations indicated that it was slightly more stable. (Note that in their paper, their notation cis/trans is apparently reversed with respect to that used here.) They found that both conformers were effectively planar. Thus, although nicotinic acid and nicotinamide are isoelectronic, their structures are different so that not only similarities but also differences in their spectra may be expected.

The ionization potentials (IP) and outermost valence ionic states of nicotinic acid and nicotinamide have been measured experimentally, ${ }^{6,7}$ and calculations of the valence bands were reported, ${ }^{7,8}$ but to the best of our knowledge, no gas-phase corelevel spectra are available. The core photoelectron and near-edge $\mathrm{X}$-ray absorption fine structure (NEXAFS) spectra of nicotinic acid adsorbed on rutile, where it is deprotonated, have been reported. ${ }^{9}$ We are not aware of any published photoelectron spectra of nicotine.

In this work, we investigate the core and valence electronic structure of this group of compounds, taking into account the

Received: December 16, 2019

Revised: April 25, 2020

Published: April 27, 2020 


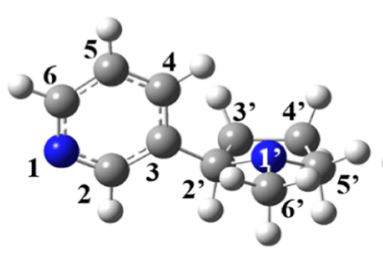

(a)

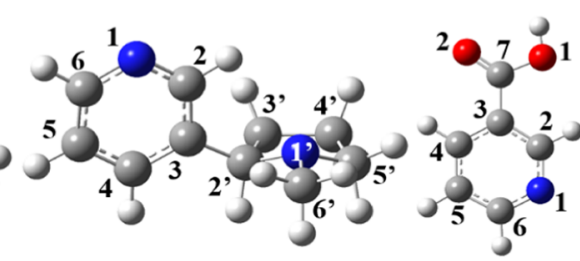

(b) (c)

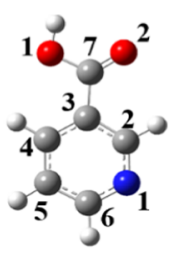

(d)

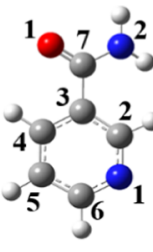

(e)

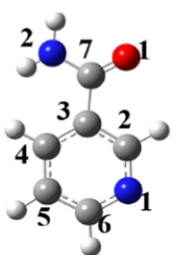

(f)

Figure 1. Schematic structures of the samples and their conformers. The atoms are labeled: gray (carbon), blue (nitrogen), red (oxygen), and white (hydrogen): (a) trans-a nicotine, (b) trans-b nicotine, (c) trans nicotinic acid, (d) cis nicotinic acid, (e) trans nicotinamide, (f) cis nicotinamide. Conformer notation for nicotine follows Grabow et al. ${ }^{1}$ For nicotinic acid and nicotinamide, cis corresponds to the carbonyl oxygen close to the pyridine nitrogen and trans corresponds to the carbonyl group far from the pyridine nitrogen. (Note that Mata et al. ${ }^{5}$ stated in their text that they used the same convention, but they labeled structures (c) and (d) as cis and trans, respectively, in their Figure 2).

Table 1. Calculated Relative Enthalpies of Formation $(\Delta E)$, Free Energies $(\Delta G)$, and Dipole Moments $(\mu)$ of the Conformers

\begin{tabular}{|c|c|c|c|c|c|c|c|}
\hline \multirow[b]{2}{*}{ conformer } & \multicolumn{4}{|c|}{ present work, theory } & \multicolumn{3}{|c|}{ literature, theory } \\
\hline & $\overline{\Delta E^{a}\left(\mathrm{~kJ} \cdot \mathrm{mol}^{-1}\right)}$ & $\Delta G\left(\mathrm{~kJ} \cdot \mathrm{mol}^{-1}\right)$ & $\mu$ (Debye) & $T(\mathrm{~K})$ & $\Delta E\left(\mathrm{~kJ} \cdot \mathrm{mol}^{-1}\right)$ & $\Delta G^{b}\left(\mathrm{~kJ} \cdot \mathrm{mol}^{-1}\right)$ & $\mu$ (Debye) \\
\hline trans-a nicotine & 0 & 0.0 & 2.638 & 298 & $0.0^{1}$ & $0.0^{2}$ & $2.6^{1}$ \\
\hline trans-b nicotine & 2.17 & 1.68 & 3.052 & 298 & $2.49^{1}$ & $1.84^{2}$ & $3.1^{1}$ \\
\hline trans nicotinic acid & 0.0 & 0.0 & 0.692 & 336 & $0.0^{5,36,37}$ & $0.0^{5}$ & $0.82,{ }^{5} 0.755,,^{35} 0.762^{37}$ \\
\hline cis nicotinic acid & 1.07 & 0.96 & 3.472 & 336 & $1.0,{ }^{5} 2.5,^{36} 1.05^{37}$ & $0.68^{5}$ & $3.30,{ }^{5,38} 3.42,{ }^{35} 3.65^{37}$ \\
\hline trans nicotinamide & 0.0 & 0.0 & 1.909 & 326 & $0.0^{39}$ & $0.0^{39}$ & $2.020,^{4} 2.107^{39}$ \\
\hline cis nicotinamide & 3.87 & 4.39 & 5.270 & 326 & $4.41^{39}$ & $4.98^{39}$ & $6.090,{ }^{4} 5.238^{39}$ \\
\hline
\end{tabular}

${ }^{a} \Delta E$ is the difference of the total electronic energies (EE) of the conformer pairs. The free energy was calculated as (EE + thermal free energy corrections). The zero-point vibrational energies of the conformer pairs of the three compounds are within $0.2 \mathrm{~kJ} \cdot \mathrm{mol}^{-1}$, which is too small to alter the order of relative stability. ${ }^{b}$ The literature value of $\Delta G$ is calculated at $298 \mathrm{~K}$.

effect of conformational isomerism. A number of studies of other molecules have been reported, ${ }^{10-15}$ in which the effects of conformation on peak shapes and binding energy shifts were observed. Generally, the effects are subtle and difficult to observe. Apart from its general importance, in the valence band region, the effects of conformational isomerism are important in dichroic photoelectron spectroscopy. ${ }^{14}$ When conformers with internal hydrogen bonds are present, for example, in amino acids, the effects are often more clearly observed, especially as a core-level shift, ${ }^{15-19}$ while the effects may be elusive in the absence of a hydrogen bond. ${ }^{20,21}$ The present compounds do not contain hydrogen bonds, and the number of isomers is restricted, two for nicotinamide and nicotinic acid, and two stable forms for nicotine.

\section{EXPERIMENTAL AND THEORETICAL METHODS}

II.I. Experimental Methods. The experiments were performed at the Gas Phase Photoemission beamline in the synchrotron light source Elettra, Trieste, Italy, using the apparatus described previously. ${ }^{22}$ The photoemission spectra were measured with a total resolution (photon + analyzer) of $0.2,0.57,0.59$, and $0.78 \mathrm{eV}$ at photon energies of $100 \mathrm{eV}$ (valence), $382 \mathrm{eV}$ (C 1s), $495 \mathrm{eV}$ (N 1s), and $628 \mathrm{eV}$ (O 1s), respectively. The energy scale of the valence band spectrum was calibrated with reference to the $\mathrm{H}_{2} \mathrm{O}$ (from residual gas) spectrum for the valence spectra, while for core-level photoemission, the spectra were referred to the following core levels and gases: $297.6 \mathrm{eV}\left(\mathrm{C} 1 \mathrm{~s}, \mathrm{CO}_{2}\right),{ }^{23} 409.9 \mathrm{eV}\left(\mathrm{N} \mathrm{1s}, \mathrm{N}_{2}\right),{ }^{24}$ and $541.3 \mathrm{eV}\left(\mathrm{O} 1 \mathrm{~s}, \mathrm{CO}_{2}\right) .{ }^{24}$ The NEXAFS spectra at the $\mathrm{C}, \mathrm{N}$, and $\mathrm{O} \mathrm{K}$ edges were acquired by measuring the total ion yield with a channel electron multiplier placed close to the ionization region. The spectra were normalized to the photon flux measured simultaneously by a photodiode. In a separate measurement, the photon energy scale was calibrated to known resonances, by measuring the spectra of a mixture of the sample and the following gases: $290.77 \mathrm{eV}\left(\mathrm{C} 1 \mathrm{~s} \rightarrow \pi^{*}, \mathrm{CO}_{2}\right),{ }^{25} 400.87 \mathrm{eV}(\mathrm{N}$ $\left.1 \mathrm{~s} \rightarrow \pi^{*}, \mathrm{~N}_{2}\right),{ }^{26}$ and $535.4 \mathrm{eV}\left(\mathrm{O} 1 \mathrm{~s} \rightarrow \pi^{*}, \mathrm{CO}_{2}\right) .^{27}$ The photon energy resolution was 70, 60, and $100 \mathrm{meV}$ at the $\mathrm{C}, \mathrm{N}$, and $\mathrm{O} \mathrm{K}$ edges, respectively.

Nicotinic acid, (-)-nicotine, and nicotinamide were purchased from Sigma-Aldrich and used without further purification. Their purities were $>99.5$, $>99$, and $>99.5 \%$, respectively. The samples were introduced into the system via an effusive needle source at room temperature (nicotine) or evaporated from a crucible at temperatures of $336 \mathrm{~K}$ (nicotinic acid) or $326 \mathrm{~K}$ (nicotinamide) and a background pressure of 1$10 \times 10^{-6}$ mbar.

II.II. Theoretical Methods. Calculations were performed for the two lowest-energy conformers of nicotine ${ }^{1}$ and both trans and cis isomers of nicotinic acid and nicotinamide. A density functional theory model, B3LYP/6-311++G**, was used in the optimizations and potential energy calculations of the three compounds and their steric isomers. Potential energy scans of the lowest-energy (global minimum energy) structures were performed as a function of the rotation angle of the pyridine-substituent bond, keeping other structural parameters constant. Outer Valence Green's Function (OVGF/6-311+ $\left.+\mathrm{G}^{* *}\right)$ calculations were performed to obtain valence orbital ionization energies, while core ionization energy calculations were performed by applying the core electron binding energy (CEBE) method, also known as the $\Delta E_{\mathrm{KS}}$ method, ${ }^{28,29}$ for the relaxed ionization energy. The CEBE method, using the (PW86PW91)/et-pVQZ model, ${ }^{30-32}$ determines the energies of the cationic states (hole states) of the molecule after core ionization. As a result, the energy difference between the specific coreionized cation and the neutral parent molecule represents the ionization energy. The CEBE method thereby takes into account core hole relaxation effects. ${ }^{30}$ No further modifications or scaling were applied. The core-level binding energy calculations (ionization potential, IP) were carried out using 
the Amsterdam Density Functional (ADF) computational chemistry program. ${ }^{33}$ Other calculations were carried out using the GAUSSIAN16 computational chemistry program. ${ }^{34}$

\section{RESULTS AND DISCUSSION}

III.I. Results: Valence Band. Nicotine is chiral and so exists as two enantiomers; in the present study, we used (-)-nicotine, the enantiomeric form occurring in the tobacco plant. Since linearly (and not circularly) polarized light was used, no effects due to chirality occur in the photoelectron spectra. In contrast, conformational effects are possible, and two conformers of nicotine have been reported to be the most stable, labeled trans$a$ and trans-b, following the notation of Grabow et al. ${ }^{1}$ (Figure 1 ). The isomers differ by a rotation of approximately $180^{\circ}$ about the $\mathrm{C}-\mathrm{C}$ bond joining the pyridine and pyrrolidine rings. We calculated the structures of these two low-energy conformers and found good agreement with ref 1 for the structural parameters. At $0 \mathrm{~K}$, we found that trans-a is more stable than trans-b by $\Delta E=2.17 \mathrm{~kJ} \cdot \mathrm{mol}^{-1}$ (Table 1$)$. Applying thermal corrections, at $298 \mathrm{~K}$ the free energy of trans-a is still lower than that of trans-b (Table 1), in agreement with Elmore and Dougherty. ${ }^{2}$

A potential energy scan for rotation around the $\mathrm{C} 22^{\prime}-\mathrm{C} 3$ bond of trans-a nicotine is shown in Figure S1 in the Supporting Information, with all other bond lengths and angles fixed. The energy barriers for rotation and, therefore, conversion from trans-a to trans-b are 31.5 and $33 \mathrm{~kJ} \cdot \mathrm{mol}^{-1}$, respectively, depending on the direction of rotation, indicating facile conversion at experimental temperatures.

Figure 2 shows the valence band ionization spectra of nicotine, and the experimental and theoretical results for the two

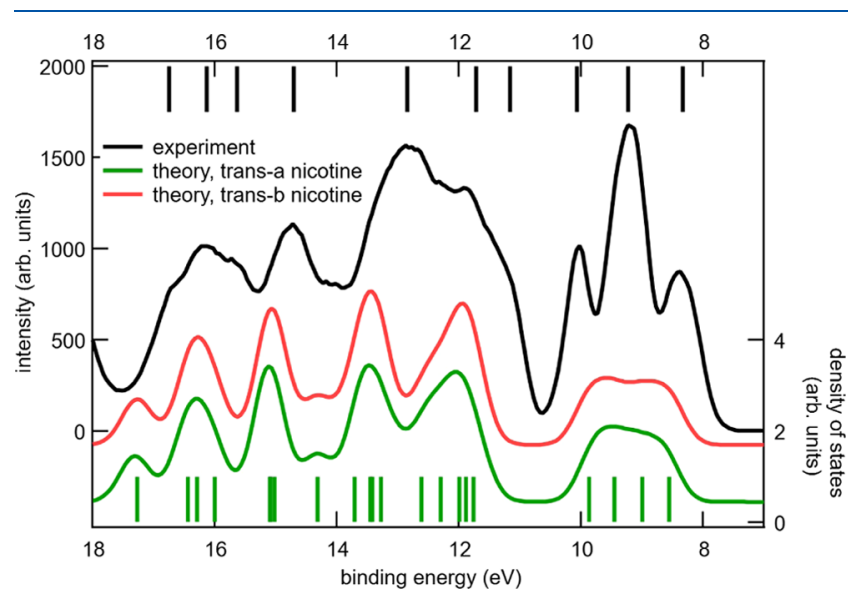

Figure 2. Theoretical density of states and experimental outer valence photoelectron spectra of nicotine. Experiment: black curve, left axis; upper black bars, experimental binding energies obtained by fitting. Theory: green (trans-a nicotine) and red (trans-b nicotine) curves, densities of states, right axis, assuming a Gaussian broadening function of $0.61 \mathrm{eV}$ full width at half maximum (FWHM). Lower green vertical bars: calculated binding energies of trans-a nicotine. Photon energy: $100 \mathrm{eV}$.

isomers are summarized in Table 2; the full list of calculated ionization energies is given in the Supporting Information (Table S1). The calculated valence binding energies of the conformers are very similar, as seen from the two curves in Figure 2. For this reason, only the values for trans-a nicotine are shown as bars in the figure. Three peaks are visible in the experimental data between 8 and $10 \mathrm{eV}$ binding energy, and the
Table 2. Outer Valence Orbital Ionization Energies (eV) of Nicotine

\begin{tabular}{lccc} 
orbital & theory $($ trans-a) & theory (trans-b) & expt. \\
$44 \mathrm{a}($ HOMO) & 8.63 & 8.55 & 8.33 \\
$43 \mathrm{a}$ & 9.05 & 8.99 & 9.22 \\
$42 \mathrm{a}$ & 9.44 & 9.45 & \\
$41 \mathrm{a}$ & 9.80 & 9.86 & 10.06 \\
$40 \mathrm{a}$ & 11.71 & 11.75 & 11.16 \\
$39 \mathrm{a}$ & 12.01 & 11.88 & 11.72 \\
$38 \mathrm{a}$ & 12.04 & 11.99 & \\
$37 \mathrm{a}$ & 12.40 & 12.30 & 12.85 \\
$36 \mathrm{a}$ & 12.60 & 12.61 & \\
\hline
\end{tabular}

theory predicts four states in this interval. The shape of the spectrum suggests that the theory overestimates the energetic difference between the second and third ionic states. The measured first ionization potential of $8.33 \mathrm{eV}$ is in good agreement with the calculated values of 8.55 and $8.63 \mathrm{eV}$, and the root mean square (rms) difference between theory and experiment for the first four ionic states is $0.22 \mathrm{eV}$ for both conformers, which also shows good agreement. Between the fourth and fifth ionic states, theory predicts a gap of $1.9 \mathrm{eV}$, but experimentally, the gap is much smaller, about $1.1 \mathrm{eV}$. At binding energies greater than $11 \mathrm{eV}$, the density of states becomes high and it is difficult to assign features, but there is qualitative agreement between the spectrum and the density of states, with a tendency for the theoretical peaks and valleys to be at several hundred millielectron volts $(\mathrm{meV})$ higher binding energy than the experimental values.

We calculated the geometric and electronic structure of nicotinic acid and found that the minimum-energy structure was planar for the heavy ( $\mathrm{O}$ and $\mathrm{N}$ ) atoms, in agreement with previous experimental $^{5}$ and theoretical ${ }^{35-39}$ works. For conversion between the two isomers by rotation about the C3-C7 bond of trans nicotinic acid, with all other structural parameters frozen, the energy barrier between the two structures (trans and cis) is $27.0 \mathrm{~kJ} \cdot \mathrm{mol}^{-1}$ (see Supporting Information Figure S2). A rapid conversion between the two isomers is to be expected at laboratory temperatures.

The calculated difference in free energy $(\Delta G)$ between the two nicotinic acid conformers at $336 \mathrm{~K}$ is small. Table 1 shows that the cis conformer of nicotinic acid is $0.96 \mathrm{~kJ} \cdot \mathrm{mol}^{-1}$ less stable than the trans conformer, in good agreement with previous calculations. ${ }^{5}$ The dipole moments are also in good agreement with published values. $5,35,37,38$

The calculated valence band spectra of the cis and trans isomers of nicotinic acid are very similar (Figure 3 ) as was the case for nicotine. The agreement with the published He I spectrum of Dougherty et al. ${ }^{6}$ is good, with the energies of the first three peaks agreeing within $0.16 \mathrm{eV}$. The vibrational structure is visible on the third peak, as reported by Dougherty et al., ${ }^{6}$ with a vibrational quantum of $0.2 \mathrm{eV}$. The experimental spectrum has a shape rather different from the density of states, which may in part be due to different cross sections of the ionic states. The results are summarized in Table 3. It can be seen that the rms difference between theory and experiment for the ionization energies is $0.25 \mathrm{eV}$, greater than that for nicotine. This is mostly due to the discrepancies for the third and fourth highest molecular orbitals, where theory apparently overestimates the energetic separation.

For nicotinamide, we calculated the minimum-energy structure and found a structure distorted from planar for both 


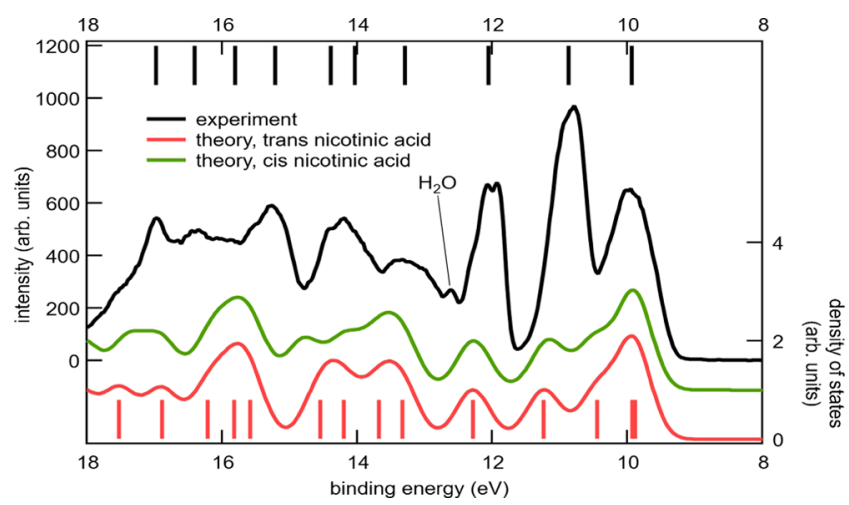

Figure 3. Theoretical density of states and experimental outer valence photoelectron spectra of nicotinic acid. Experiment: black curve, left axis; upper black bars, experimental binding energies obtained by fitting. Theory: red (trans nicotinic acid) and green (cis nicotinic acid) curves, densities of states, right axis, assuming a Gaussian broadening function of $0.61 \mathrm{eV}$ FWHM. Lower red vertical bars: calculated binding energies of trans nicotinic acid. Photon energy: $100 \mathrm{eV}$.

Table 3. Outer Valence Orbital Ionization Energies $(\mathrm{eV})$ of Nicotinic Acid

\begin{tabular}{lrrrrr}
$\begin{array}{l}\text { orbital label, } C_{s} \\
\text { symmetry }\end{array}$ & $\begin{array}{r}\text { theory } \\
\text { (trans) }\end{array}$ & $\begin{array}{c}\text { theory } \\
\text { (cis) }\end{array}$ & $\begin{array}{c}\Delta \mathrm{IP} \\
\text { (trans-cis) }\end{array}$ & $\begin{array}{c}\text { Dougherty et } \\
\text { al. }^{6}\end{array}$ \\
\hline $5 \mathrm{a}^{\prime \prime}$ (HOMO) & 9.89 & 9.85 & 0.04 & 9.94 & 10.0 \\
$4 \mathrm{a}^{\prime \prime}$ & 9.93 & 9.94 & -0.01 & & \\
$27 \mathrm{a}^{\prime}$ & 10.45 & 10.49 & -0.04 & 10.87 & $10.77,10.93$ \\
$26 \mathrm{a}^{\prime}$ & 11.24 & 11.17 & 0.07 & & \\
$3 \mathrm{a}^{\prime \prime}$ & 12.29 & 12.27 & 0.02 & 12.6 & 11.90 \\
$25 \mathrm{a}^{\prime}$ & 13.33 & 13.33 & 0.0 & 13.29 & \\
$2 \mathrm{a}^{\prime \prime}$ & 13.68 & 13.69 & -0.01 & & \\
$24 \mathrm{a}^{\prime}$ & 14.20 & 14.19 & 0.01 & 14.39 & \\
$23 \mathrm{a}^{\prime}$ & 14.54 & 14.79 & -0.25 & & \\
$22 \mathrm{a}^{\prime}$ & 15.58 & 15.54 & 0.04 & 15.21 & \\
$1 \mathrm{a}^{\prime \prime}$ & 15.82 & 15.82 & 0.0 & 15.81 & \\
$21 \mathrm{a}^{\prime}$ & 16.21 & 16.18 & 0.03 & 16.41 & \\
$20 \mathrm{a}^{\prime}$ & 16.89 & 16.90 & -0.01 & 16.98 & \\
$19 \mathrm{a}^{\prime}$ & 17.52 & 17.40 & 0.12 & - & \\
$18 \mathrm{a}^{\prime}$ & 18.15 & 18.08 & 0.07 & - &
\end{tabular}

the cis and trans conformers, with the carboxamide group twisted with respect to the pyridine plane, and with $C_{1}$ molecular point group symmetry. This result is in agreement with the experimental results of Vogelsanger et al. ${ }^{4}$ and calculations of Kumar et al. ${ }^{39}$ A potential energy scan is shown in Figure S3 of the Supporting Information, performed by fixing all structural parameters except the rotation angle around the $\mathrm{C} 3-\mathrm{C} 7$ bond of the trans nicotinamide. The stable rotation angles were found to be $160^{\circ}$ for trans and $23^{\circ}$ for cis, compared to the experimental values ${ }^{4}$ of 166 and $22^{\circ}$, respectively, and the values calculated by Kumar et al. ${ }^{39}$ of 159.5 and $24^{\circ}$, respectively. The energy barrier to rotation was found to be $14.2 \mathrm{~kJ} \cdot \mathrm{mol}^{-1}$.

The outer valence ionization potentials of nicotinamide are listed in Table 4, and the energies of the first three valence ionization peaks of nicotinamide (Figure 4) are in agreement with those reported by Dougherty et al., ${ }^{6}$ measured with He I radiation. The relative intensities of the peaks are different due to the different photon energies used (and therefore different cross sections). The theoretical difference between first ionization energies of the two conformers of nicotinamide, $0.09 \mathrm{eV}$, is slightly larger than that for nicotinic acid (Table 3), and the free-energy difference of $4.39 \mathrm{~kJ} \cdot \mathrm{mol}^{-1}$ (Table 1)
Table 4. Outer Valence Orbital Ionization Energies (eV) of Nicotinamide

\begin{tabular}{crrrrc} 
orbital & $\begin{array}{r}\text { theory } \\
\text { (trans) }\end{array}$ & $\begin{array}{c}\text { theory } \\
\text { (cis) }\end{array}$ & $\begin{array}{c}\Delta \text { IP } \\
\text { (trans-cis) }\end{array}$ & $\begin{array}{c}\text { Dougherty et } \\
\text { al. }^{6}\end{array}$ \\
\hline $32 \mathrm{a}$ & 9.78 & 9.69 & 0.09 & 9.71 & 9.85 \\
31a & 10.10 & 9.84 & 0.26 & & \\
$30 \mathrm{a}$ & 10.15 & 10.34 & -0.19 & 10.26 & 10.35 \\
$29 \mathrm{a}$ & 10.29 & 10.43 & -0.14 & & \\
$28 \mathrm{a}$ & 10.65 & 10.58 & 0.07 & 10.67 & 10.75 \\
$27 \mathrm{a}$ & 13.24 & 13.25 & -0.01 & 13.07 & \\
$26 \mathrm{a}$ & 13.49 & 13.48 & 0.01 & & \\
$25 \mathrm{a}$ & 14.07 & 14.44 & -0.37 & 14.17 & \\
$24 \mathrm{a}$ & 14.60 & 14.41 & 0.19 & 14.54 & \\
$23 \mathrm{a}$ & 14.89 & 14.97 & -0.08 & 15.10 & \\
$22 \mathrm{a}$ & 15.43 & 15.44 & -0.01 & 15.66 & \\
$21 \mathrm{a}$ & 16.11 & 16.04 & 0.07 & 16.31 & \\
$20 \mathrm{a}$ & 16.91 & 16.77 & 0.14 & 17.00 & \\
$19 \mathrm{a}$ & 17.65 & 17.63 & 0.02 & & \\
$18 \mathrm{a}$ & 18.62 & 18.63 & -0.01 & 18.23 & \\
\hline
\end{tabular}

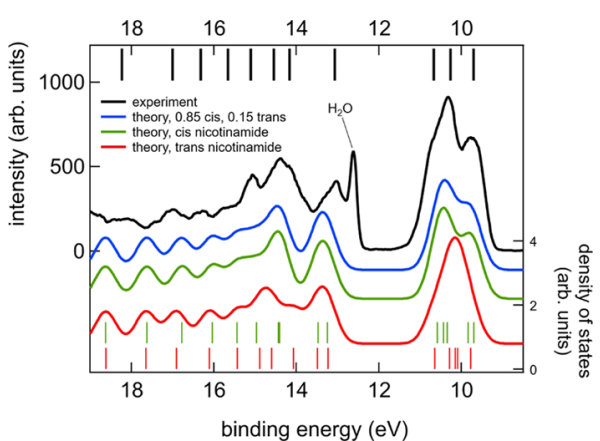

Figure 4. Theoretical density of states and experimental outer valence photoelectron spectra of nicotinamide. Experiment: black curve, left axis; upper black bars, experimental binding energies obtained by fitting. Theory: red (trans nicotinamide) and green (cis nicotinamide) curves, densities of states, right axis, assuming a Gaussian broadening function of $0.61 \mathrm{eV}$ FWHM. Lower red vertical bars: calculated binding energies of trans nicotinamide; lower green vertical bars: calculated binding energies of cis nicotinamide. Blue curve: simulated density of states for a mixture of cis/trans with a population ratio of $0.85: 0.15$. Photon energy: $100 \mathrm{eV}$.

suggests that the population of the trans conformer may dominate. The calculated density of states of cis nicotinamide agrees slightly better with experiment than the trans form, particularly for the outermost states, and around $14 \mathrm{eV}$ binding energy. However, we calculated that the trans form was more stable by a free-energy difference of $4.39 \mathrm{~kJ} \cdot \mathrm{mol}^{-1}$ at the temperature of the experiment $(326 \mathrm{~K})$. This corresponds to a population ratio of $0.83: 0.17$. In Figure 4, the blue curve shows a simulation for a cis/trans population ratio of 0.85:0.15, which appears to agree reasonably well with the experiment. This value of population ratio corresponds to a free-energy difference of 4.7 $\mathrm{kJ} \cdot \mathrm{mol}^{-1}$. We conclude that the trans species is more stable by a few $\mathrm{kJ} \cdot \mathrm{mol}^{-1}$, but it is difficult to quantify this value. Vogelsanger et al. ${ }^{4}$ observed approximately equal populations of the two conformers at their temperature of $433-443 \mathrm{~K}$. Their result agrees qualitatively with the present result, as Vogelsanger et al. noted that their estimate was approximate, due to uncertainties such as the temperature of their molecular beam.

Nicotinic acid and nicotinamide are isoelectronic, both contain a pyridine ring and display some differences and 


\begin{tabular}{|c|c|c|c|c|c|}
\hline Nicotinic acid (trans) & $5 \mathrm{a} " \mathrm{IP}=9.89 \mathrm{eV}$ & $4 \mathrm{a} " \mathrm{IP}=9.93 \mathrm{eV}$ & $27 a^{\prime} \mathrm{IP}=10.45 \mathrm{eV}$ & $26 \mathrm{a}^{\prime} \mathrm{IP}=11.24 \mathrm{eV}$ & $3 \mathrm{a} " \mathrm{IP}=12.29 \mathrm{eV}$ \\
\hline Nicotinic acid (cis) & $5 \mathrm{a} " \mathrm{IP}=9.85 \mathrm{eV}$ & $4 \mathrm{a} " \mathrm{IP}=9.94 \mathrm{eV}$ & $27 \mathrm{a}^{\prime} \mathrm{IP}=10.49 \mathrm{eV}$ & $26 \mathrm{a}^{\prime} \mathrm{IP}=11.17 \mathrm{eV}$ & $3 \mathrm{a} " \mathrm{IP}=12.27 \mathrm{eV}$ \\
\hline Nicotinamide (trans) & $32 \mathrm{a} \mathrm{IP}=9.78 \mathrm{eV}$ & $31 \mathrm{a} \mathrm{IP}=10.10 \mathrm{eV}$ & $30 \mathrm{a} \mathrm{IP}=10.15 \mathrm{eV}$ & $29 \mathrm{a} \mathrm{IP}=10.29 \mathrm{eV}$ & $28 \mathrm{a} \mathrm{IP}=10.65 \mathrm{eV}$ \\
\hline Nicotinamide (cis) & $32 \mathrm{a} \mathrm{IP}=9.69 \mathrm{eV}$ & $31 \mathrm{a} \mathrm{IP}=9.84 \mathrm{eV}$ & $30 \mathrm{a} I \mathrm{IP}=10.34 \mathrm{eV}$ & $29 \mathrm{a} I P=10.43 \mathrm{eV}$ & $28 \mathrm{a} I \mathrm{IP}=10.58 \mathrm{eV}$ \\
\hline
\end{tabular}

Figure 5. Comparison of the charge distributions of the outermost five valence states of trans and cis conformers of nicotinic acid and nicotinamide. The charge distributions are based on HF calculations, and the ionization potentials are derived from OVGF calculations.

similarities in their outer valence spectra. Figure 5 compares the theoretical orbital charge distributions of the first five outermost orbitals of the trans and cis conformers of nicotinic acid and nicotinamide from Hartree-Fock (HF) calculations, while the orbital energies are based on OVGF. The highest occupied molecular orbitals (HOMOs) of both rotamers of nicotinic acid $\left(5 \mathrm{a}^{\prime \prime}\right)$ and nicotinamide (32a) are delocalized orbitals with significant weight on the pyridine ring and the carbonyl group. Both the charge distributions and the ionization energies are similar.

The HOMO-1 (4a") orbital of nicotinic acid has largely pyridine $\pi$ orbital character, with little carboxylic character, whereas the HOMO-1 (31a) and HOMO-2 (30a) orbitals of nicotinamide have pyridine $\pi$ orbital character with a strong admixture of states localized on the carboxamide moiety. The HOMO-3 (26a') and HOMO-4 (3a') orbitals of nicotinic acid show some similarity to the HOMO-4 (28a) orbital of nicotinamide, but with a reversal of the previous trend. All have significant pyridine character, but nicotinic acid has a stronger admixture of states localized on the carboxylic moiety, while the HOMO-4 (28a) of nicotinamide has a small contribution from the carboxamide group. The nonplanarity of nicotinamide perturbs the $\pi$ bonding compared to nicotinic acid. This influences primarily the hybridization of the pyridine orbitals with the carboxamide group, most evident in the orbitals of HOMO-1 (31a), HOMO-2 (30a), and HOMO-3 (29a) of nicotinamide in Figure 5.

Turning now to the differences between rotamers of each species, the charge distributions of the two highest occupied molecular orbitals of nicotinic acid appear to be the sums of the charge on the two moieties. For HOMO-2 (27a'), this is no longer the case and there are clear indications of redistribution of charge within the chromophores. The charge distributions in the next orbital $\left(26 \mathrm{a}^{\prime}\right)$ are again similar, while they diverge for HOMO-4 ( $\left.3 \mathrm{a}^{\prime \prime}\right)$. There appears to be no intuitive chemical argument to predict these trends, as they can only be observed via calculations.

For nicotinamide, the charge density distributions are rather similar (in the above sense) for the HOMO, HOMO-3 and HOMO-4 cis and trans forms. For the HOMO- 1 orbital, the cis form shows a reduction of charge on the pyridine ring and an increase on the carboxamide group compared to trans. For HOMO-2, it is vice versa, with the pyridine accumulating charge.

The charge distributions of the outermost orbitals of nicotine are shown in Figure S4, Supporting Information. The corresponding orbitals of the two conformers have similar characters and tend to be localized on the methylpyrrolidine moiety (HOMO, HOMO-4) or the pyridine moiety (HOMO1, HOMO-2, HOMO-3) with only minor mixing between the electron systems of the two rings. This is understandable, given 
that they are linked by a $\sigma$ bond, and delocalized $\pi$ bonding is not facilitated.

III.II. Results: Core Levels. The carbon C 1s spectra of the three compounds are shown in Figure 6, and the experimental

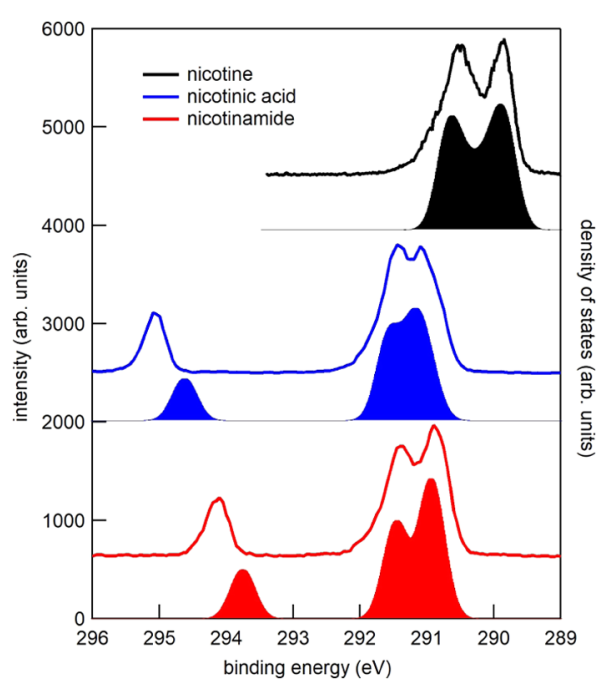

Figure 6. C 1s core-level spectra (left axis) and the theoretical density of states (right axis; plotted below each experimental curve). Each ionic state is assumed to have the same intensity and width $(0.4 \mathrm{eV})$. The theoretical curve of nicotine has been shifted to lower binding energy by $0.55 \mathrm{eV}$. Photon energy: $382 \mathrm{eV}$ for nicotine and $390 \mathrm{eV}$ for nicotinic acid and nicotinamide.

and theoretical data are shown in Table 5. For nicotine, only two C 1s peaks are resolved experimentally for ionization of the 10 carbon atoms. These were fitted with two Gaussian peaks, and the narrower peak has a binding energy of $289.86 \mathrm{eV}$, while the broader peak has an energy of $290.50 \mathrm{eV}$. The calculations predict that atoms $\mathrm{C} 3, \mathrm{C} 4$, and $\mathrm{C} 5$ in the pyridine ring, and $\mathrm{C} 3{ }^{\prime}$ and $\mathrm{C}^{\prime}$ have the lowest binding energy, and the $289.86 \mathrm{eV}$ peak is assigned accordingly. The broader peak is assigned to ionization of all other carbon atoms. As expected from charge transfer arguments, all five of the carbon atoms bonded to nitrogen are predicted to have higher binding energy than the other carbon atoms. The theoretical curve, rigidly shifted by 0.4 $\mathrm{eV}$, reproduces the double-peak shape of the experimental spectrum. The calculations indicate that the differences in binding energy between the two conformers are very small, with $\mathrm{C} 4$ showing the greatest shift of $80 \mathrm{meV}$ and all others being smaller. Due to the large number of core levels and small shifts, it is unlikely that differences between conformers can be observed for this molecule.

The experimental and theoretical C 1s core spectra of nicotinic acid and nicotinamide in Figure 6 both display three main peaks, with an additional weak shoulder on the lower binding energy side of the nicotinic acid experimental spectrum. The nicotinic acid spectrum was fitted with four Gaussian peaks of variable width and intensity, while the nicotinamide spectrum was fitted with three peaks. Fitting of the nicotinic acid spectrum yielded peaks at binding energies of 290.86, 291.07, 291.45, and $295.07 \mathrm{eV}$, with integrated intensity ratios of 1.05:0.83:3.11:1.02. See Supporting Information Figure S6 for the individual fitted peaks and their sum. This is not as close to stoichiometric as may be desired, but the presence of the lowenergy shoulder in the experimental data suggests that four peaks are indeed required to describe the spectrum. The lowest binding energy peaks are assigned to $\mathrm{C} 5$ and $\mathrm{C} 3$, while $\mathrm{C} 2, \mathrm{C} 4$, and C6 are assigned to the peak at the binding energy of 291.45 $\mathrm{eV}$. For the five-ring carbon binding energies, the rms difference between theory and experiment is $0.14 \mathrm{eV}$ for the trans conformer and $0.16 \mathrm{eV}$ for the cis conformer, indicating that we cannot distinguish them. The carboxylic carbon has the highest binding energy $(295.07 \mathrm{eV})$.

For nicotinamide, the fit yielded peaks at $290.83,291.38$, and $294.14 \mathrm{eV}$ with integrated intensity ratios of 2:3:1 (see Supporting Information Figure S6). The highest binding energy peak is assigned to $\mathrm{C} 7$, in the carboxamide group. The lowest binding energy peak is assigned to C3 and C5, and the $291.38 \mathrm{eV}$ peak to C2, C4, and C6. Since C2 and C6 are adjacent to the electronegative nitrogen atom, it is clear that inductive effects will lead to higher binding energies for these atoms. C4 is in the para position with respect to this nitrogen atom, and so it is more likely to be affected by resonance phenomena. The calculated binding energy of $\mathrm{C} 4$ is significantly different for the cis and trans isomers, and the theoretical value for the trans conformer agrees better with the experiment. For the five-ring carbon binding energies, the rms difference between theory and experiment is $0.12 \mathrm{eV}$ for the trans conformer and $0.20 \mathrm{eV}$ for the cis conformer. This suggests that the trans conformer is

Table 5. Calculated and Experimental C, N, and O 1s Binding Energies for the Conformers of the Three Compounds

\begin{tabular}{|c|c|c|c|c|c|c|c|}
\hline \multicolumn{4}{|c|}{ nicotinamide } & \multicolumn{4}{|c|}{ nicotinic acid } \\
\hline core & expt. & theory, cis & theory, trans & core & expt. & theory, cis & theory, trans \\
\hline N1 & 405.00 & 404.82 & 404.78 & N1 & 405.05 & 404.91 & 404.92 \\
\hline $\mathrm{N} 2$ & 406.00 & 406.10 & 406.11 & $\mathrm{O} 1$ & 540.1 & 539.92 & 539.91 \\
\hline $\mathrm{O}$ & 537.20 & 536.92 & 536.93 & $\mathrm{O} 2$ & 538.1 & 537.67 & 537.66 \\
\hline $\mathrm{C} 2$ & 291.38 & 291.50 & 291.33 & $\mathrm{C} 2$ & 291.45 & 291.56 & 291.53 \\
\hline $\mathrm{C} 3$ & 290.83 & 290.97 & 290.97 & C3 & 291.07 & 291.20 & 291.21 \\
\hline $\mathrm{C} 4$ & 291.38 & 290.97 & 291.18 & $\mathrm{C} 4$ & 291.45 & 291.18 & 291.23 \\
\hline $\mathrm{C} 5$ & 290.83 & 290.84 & 290.89 & $\mathrm{C} 5$ & 290.86 & 290.97 & 290.98 \\
\hline C6 & 291.38 & 291.42 & 291.41 & C6 & 291.45 & 291.57 & 291.56 \\
\hline $\mathrm{C} 7$ & 294.14 & 293.75 & 293.75 & $\mathrm{C} 7$ & 295.07 & 294.62 & 294.62 \\
\hline
\end{tabular}

\begin{tabular}{lccc}
\multicolumn{3}{c}{ nicotine } \\
\hline core & expt. & theory trans-b & theory trans-a \\
N1 & 404.50 & 404.29 & 404.27 \\
N1 $^{\prime}$ & 404.50 & 404.55 & 404.52 \\
& & & \\
C2 & 290.50 & 290.81 & 290.73 \\
C3 & 289.86 & 290.36 & 290.36 \\
C4 & 289.86 & 290.42 & 290.50 \\
C5 & 289.86 & 290.36 & 290.37 \\
C6 & 290.50 & 290.87 & 290.85 \\
& & & \\
C2 & 290.86 & 291.22 & 291.22 \\
C3 $^{\prime}$ & 290.50 & 290.46 & 290.45 \\
C4 $^{\prime}$ & 290.50 & 290.58 & 290.56 \\
C5 $^{\prime}$ & 290.86 & 291.16 & 291.14 \\
C6 $^{\prime}$ & 290.86 & 291.21 & 291.19
\end{tabular}


dominant, but since the peaks are not fully resolved, this conclusion is tentative. This result is consistent with the calculated free energies, which predict that trans is more stable, but inconsistent with the valence data above, which suggest that the cis form is more stable.

The N 1s spectra are shown in Figure 7, and the data are summarized in Table 5, together with the $\mathrm{O} 1 \mathrm{~s}$ binding energies.

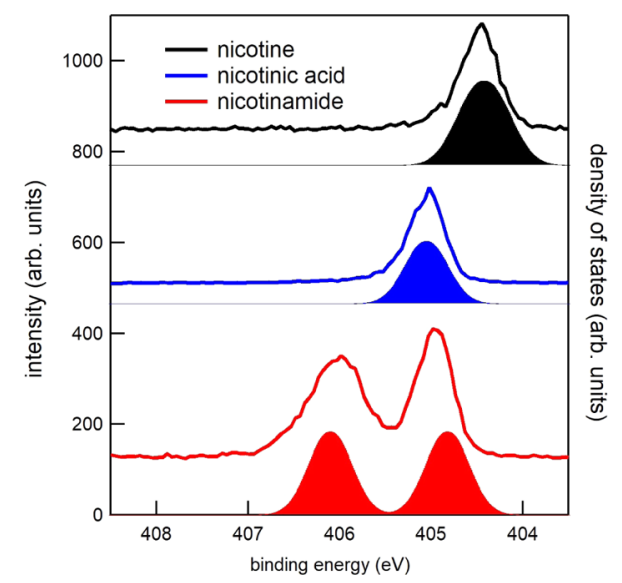

Figure 7. N 1s core-level spectra (left axis) and the theoretical density of states (right axis; plotted below each experimental curve). Each ionic state is assumed to have the same intensity and width $(0.4 \mathrm{eV})$. Photon energy: $495 \mathrm{eV}$ for nicotine and nicotinamide, $502 \mathrm{eV}$ for nicotinic acid.

The fitted peaks from which the binding energies were extracted are shown in Figure S7, Supporting Information. The two ionic states of nicotine are not resolved, and give rise to a single peak, at a binding energy that is predicted well by theory. The $\mathrm{N} 1 \mathrm{~s}$ binding energy of the atom in the pyridine ring is lower than that of the other two compounds by about $0.5 \mathrm{eV}$. This can be explained by the fact that the substituents of nicotinamide and nicotinic acid are strongly electronegative, and so withdraw charge from the pyridine ring, while the methylpyrrolidine moiety of nicotine is an electron donor. The $\mathrm{N} \mathrm{1s}$ binding energies of nicotinamide and nicotinic acid are in good agreement with the theoretical calculations. As expected, N2 of nicotinamide has the highest binding energy due to its proximity to $\mathrm{O} 1$.

The measured (see Supporting Information Figure S5) and calculated $\mathrm{O} 1 \mathrm{~s}$ binding energies are in good agreement. Like the other core levels, they show only weak differences between different conformers.

III.III. Results: Near-Edge X-ray Absorption Fine Structure Spectra. For the NEXAFS spectra, we have not performed calculations but assigned the spectra by comparing with published spectra of related compounds. The oxygen edge spectra are shown in Figure 8 and summarized in Table 6. The $\mathrm{O}$ $\mathrm{K}$ edge spectrum of nicotinic acid derives from the carboxylic acid group and can be compared with the spectrum of formic acid. $^{40,41}$ Peak $\mathrm{A}$ is due to the $\pi^{*}(\mathrm{C}=\mathrm{O})$ carbonyl $\mathrm{O} 2$ atom, and peak $\mathrm{B}$ is due to the $\pi^{*}(\mathrm{OH})$ hydroxyl $\mathrm{O} 1$ oxygen atom. In formic acid, the second peak in the NEXAFS spectrum is due to two overlapping resonances: excitation of the hydroxyl O1 core to either $\pi^{*}(\mathrm{OH})$ or $3 \mathrm{~s}^{*}(\mathrm{OH})$ orbital. We assign peaks B and C of nicotinic acid to a splitting of these resonances, which could occur because the $\pi^{*}$ orbital of the carboxylic group mixes with the empty $\pi^{*}$ states of the pyridine ring. For a bonding interaction, $\pi^{*}$ will move to lower energy than the $3 \mathrm{~s}^{*}$ state.

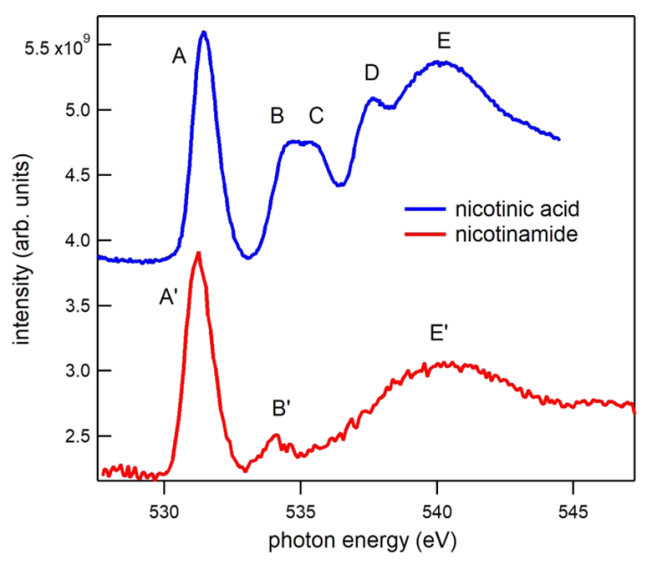

Figure 8. Oxygen near-edge $\mathrm{X}$-ray absorption fine structure spectra of the two oxygen-containing molecules.

Table 6. Energies of O K NEXAFS Spectral Features of Nicotinic Acid, Nicotinamide, and Reference Compounds

\begin{tabular}{|c|c|c|c|}
\hline \multirow[t]{2}{*}{ peak } & \multirow{2}{*}{$\begin{array}{c}\begin{array}{c}\text { resonance energy } \\
(\mathrm{eV}) / \text { term value }\end{array} \\
(\mathrm{eV}) \text {, present data }\end{array}$} & \multicolumn{2}{|c|}{$\begin{array}{l}\text { resonance energy }(\mathrm{eV}) / \text { term value }(\mathrm{eV}) \text {, } \\
\text { reference compounds }\end{array}$} \\
\hline & & formic acid & assignment \\
\hline A & $531.5 / 6.6$ & $532.1 / 6.9,^{40} 532.17 / 6.78^{41}$ & $\pi^{*}(\mathrm{C}=\mathrm{O})$ \\
\hline B & $534.7 / 5.4$ & $535.3 / 5.4,^{40} 535.37 / 5.28^{41}$ & $\pi^{*}(\mathrm{OH})$ \\
\hline $\mathrm{C}$ & $535.4 / 4.7$ & $535.3 / 5.4^{40} 535.37 / 5.28^{41}$ & $3 \mathrm{~s} *(\mathrm{OH})$ \\
\hline $\mathrm{D}$ & $537.7 / 2.4$ & $537.6 / 1.4^{40} 538.37 / 2.28^{41}$ & $\begin{array}{c}\text { higher Rydberg } \\
\text { states }(\mathrm{OH})\end{array}$ \\
\hline IP & $538.1,540.1$ & $\begin{array}{l}538.95(\mathrm{OH}), 540.65(\mathrm{C}= \\
\mathrm{O})^{42}\end{array}$ & \\
\hline $\mathrm{E}$ & 540.2 & $542.3^{41}$ & $\sigma^{*}(\mathrm{C}-\mathrm{O})$ \\
\hline & nicotinamide & formamide $\mathrm{e}^{40}$ & \\
\hline $\mathrm{A}^{\prime}$ & $531.3 / 5.9$ & $531.5 / 6.24$ & $\pi^{*}(\mathrm{C}=\mathrm{O})$ \\
\hline $\mathrm{B}^{\prime}$ & $534.1 / 3.1$ & $533.8 / 3.94$ & $3 \mathrm{~s} / \sigma^{*}(\mathrm{HCN})$ \\
\hline IP & 537.2 & $537.74^{43}$ & \\
\hline $\mathrm{E}^{\prime}$ & 540.3 & 541.8 & $\sigma^{*}(\mathrm{C}-\mathrm{N})$ \\
\hline
\end{tabular}

The energies of the first two resonances are shifted by $0.6 \mathrm{eV}$ to lower energy compared to formic acid, and the term values are shifted by a smaller amount, $0.2-0.3 \mathrm{eV}$. Although peak $\mathrm{C}$ has a similar resonance energy to the unresolved peak of formic acid, the term value is lower by about $0.6 \mathrm{eV}$, supporting the hypothesis of $\pi^{*}-\pi^{*}$ interaction.

The higher Rydberg states however are at the same energy as those of formic acid within $0.1 \mathrm{eV}$. The larger shift with respect to the Rydberg states indicates hybridization of the antibonding states with the pyridine moiety, possibly through hyperconjugation. Resonance $\mathrm{E}$ is assigned to a shape resonance with antibonding $\sigma$ character.

The $\pi^{*}$ carbonyl resonance of nicotinamide $\left(\mathrm{A}^{\prime}\right)$ has an energy $0.2 \mathrm{eV}$ lower than formamide, ${ }^{40}$ while the $3 \mathrm{~s} / \sigma^{*}(\mathrm{HCN})$ $\left(B^{\prime}\right)$ resonance has an energy $0.3 \mathrm{eV}$ higher. The term values are however much lower than those for both formamide and nicotinic acid. This is consistent with the structure of the molecule, in which the substituent is twisted out of the plane of the pyridine ring, thus reducing the overlap between the $\pi$ orbitals. For peak B', as in the case of formamide, at the $\mathrm{O} \mathrm{K}$ edge, this peak is much weaker than the $\pi^{*}$ resonance because the antibonding orbital is mostly located on the $\mathrm{H}, \mathrm{C}$, and $\mathrm{N}$ atoms. There are no features corresponding to $\mathrm{C}$ and $\mathrm{D}$ in nicotinic acid, confirming that they originate from transitions from the $\mathrm{OH}$ core level. 
The nitrogen $\mathrm{K}$ edge spectra are shown in Figure 9, and the resonances are listed in Table 7 . Nitrogen in the pyridine ring

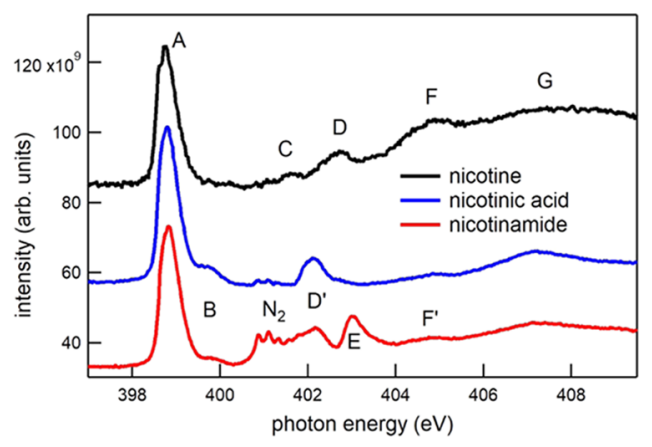

Figure 9. Nitrogen near-edge X-ray absorption fine structure spectra of nicotine, nicotinic acid, and nicotinamide.

contributes spectral features in all compounds, with additional resonances due to the primary and secondary amino groups in nicotinamide and nicotine, respectively. The $\mathrm{N} \mathrm{K}$ edge spectra of pyridine have been published by Horsley et al., ${ }^{44}$ Vall-llosera et al., ${ }^{45}$ and Baiardi et al., ${ }^{46}$ and the spectra of the present compounds are dominated by features due to the pyridine ring; in particular, the peaks labeled A, D, F, and G have the same energy (to within $200 \mathrm{meV}$ ) as corresponding features in pyridine and are therefore assigned to the same transitions. Nicotine shows a weak additional feature $\mathrm{C}$ at $401.7 \mathrm{eV}$, which may be due to the nitrogen in the methylpyrrolidine ring. Pyrrolidine shows a transition to $\pi^{*}\left(3 b_{1}\right)$ at an energy of 401.5 $\mathrm{eV}^{47}$ while nitrogen in the pyrrolidine moiety of the amino acid proline shows a corresponding transition at $401.1 \mathrm{eV}{ }^{48} \mathrm{We}$ therefore tentatively assign the feature $\mathrm{C}$ of nicotine to a transition to unoccupied states of $\sigma^{*} \mathrm{NH}$ character.

Nicotinic acid and nicotinamide both show a feature B that is not observed for pyridine and nicotine. We suggest that this is due to $\mathrm{N} 1 \mathrm{~s}$ transitions to a delocalized $\pi^{*}$ state formed by the mixing of the ring and substituent $\pi^{*}$ states, which (as seen above) splits and shifts the $\mathrm{O} \mathrm{K}$ edge resonances. Peak B is stronger in nicotinic acid than in nicotinamide, as expected, since nicotinic acid is planar, while nicotinamide is twisted, reducing the $\pi^{*}-\pi^{*}$ interaction.

The peaks $\mathrm{D}$ and $\mathrm{D}^{\prime}$ in the three compounds may have the same origin, that is, transitions to $\pi^{*}\left(b_{2}\right)$ states as in pyridine. The larger term values than for pyridine may also be due to the interaction of the $\pi^{*}$ systems.
The carbon NEXAFS spectra are shown in Figure 10, and the data are summarized in Table 8 . Because of the many possible

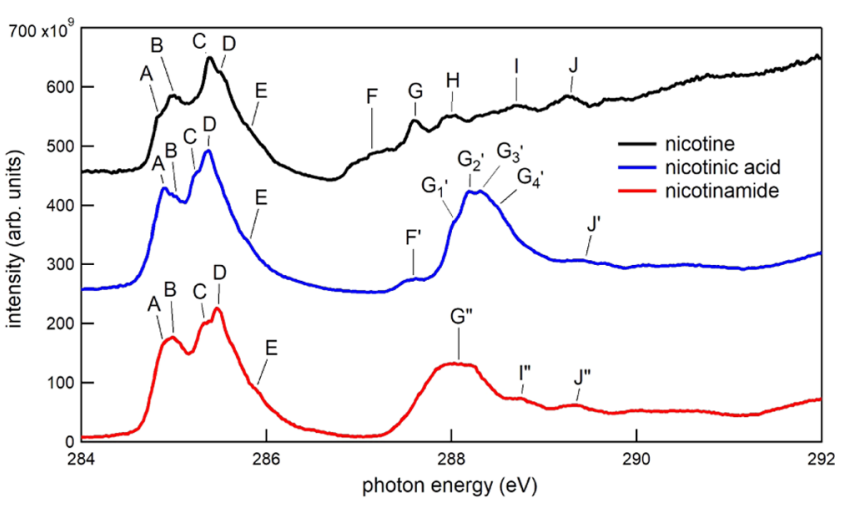

Figure 10. Carbon near-edge $\mathrm{X}$-ray absorption fine structure spectra of nicotine, nicotinic acid, and nicotinamide.

core states, it is not possible to calculate term values with a reasonable degree of confidence, so these are not included. In all compounds, the features $\mathrm{A}$ to $\mathrm{F}$ are associated with transitions from carbon atoms in the pyridine ring. All substituents are attached at the $\mathrm{C} 3$ position but give rise to different shifts in carbon core levels and thus corresponding shifts in the NEXAFS spectra. The strong features $\mathrm{F}^{\prime}$ to $\mathrm{J}^{\prime}$ in nicotinic acid and $\mathrm{G}^{\prime \prime}$ to $\mathrm{J}^{\prime \prime}$ in nicotinamide are associated mainly with the carboxylic and carboxamide carbon, respectively. The weak features F-J of nicotine are assigned to excitations in the methylpyrrolidine moiety, as they have no corresponding features in the other two spectra.

\section{CONCLUSIONS}

The valence and core electronic spectra of three pyridine derivatives have been measured, and assigned using accurate quantum mechanical calculations. Calculations reveal that the electronic structures of the cis and trans conformers of nicotinic acid, and the trans-a and trans-b conformers of nicotine, are similar. The theoretical outer valence spectra of the cis and trans conformers of nicotinamide differ significantly, and the calculated free-energy difference at the experimental temperature is small. However, the trans conformer is predicted to be more stable by a few $\mathrm{kJ} \cdot \mathrm{mol}^{-1}$, in disagreement with the experiment. Further studies with structural probes, such as microwave spectroscopy, would help to resolve this issue.

For the core electron spectra, the $\mathrm{C} 1 \mathrm{~s}$ binding energies of the cis and trans conformers of nicotinic acid and nicotinamide are

Table 7. Energies of N K NEXAFS Spectral Features of Nicotinic Acid, Nicotinamide, and Pyridine

\begin{tabular}{|c|c|c|c|c|c|}
\hline \multirow[b]{2}{*}{ peak } & \multicolumn{3}{|c|}{ resonance energy $(\mathrm{eV}) /$ term value $(\mathrm{eV})$, present data } & \multicolumn{2}{|c|}{ resonance energy $(\mathrm{eV}) /$ term value $(\mathrm{eV})$, reference compound } \\
\hline & nicotine & nicotinic acid & nicotinamide & pyridine (literature) & assignment \\
\hline A & $398.8 / 6.7$ & $398.8 / 6.25$ & $398.85 / 6.15$ & $398.8 / 6.1,^{44} 398.8 / 6.1^{45}$ & $\pi^{*}\left(\mathrm{~b}_{1}\right)^{45}$ \\
\hline B & & $399.6 / 5.45$ & $399.75 / 5.25$ & & see text \\
\hline $\mathrm{N}_{2}$ & & $\sim 401$ & $\sim 401$ & & $\mathrm{~N}_{2}$ in residual gas \\
\hline $\mathrm{C}$ & $401.7 / 3.8$ & & & & $\sigma^{*} \mathrm{NH}$ (pyrrolidine) \\
\hline $\mathrm{D}^{\prime}$ & & $402.1 / 2.95$ & $402.2 / 2.8$ & $402.7 / 2.2,,^{44} 402.6 / 2.3^{45}$ & $\pi^{*}\left(\mathrm{~b}_{2}\right)^{45}$ \\
\hline $\mathrm{D}$ & $402.8 / 2.7$ & & & $402.7 / 2.2,,^{44} 402.6 / 2.3^{45}$ & $\pi^{*}\left(\mathrm{~b}_{2}\right)^{45}$ \\
\hline $\mathrm{E}$ & & & $403 / 3.0$ & & $3 \mathrm{~s} / \sigma^{*}(\mathrm{HCN})^{40}$ \\
\hline $\mathrm{F}$ & $405.1 / 0.4$ & $405.0 / 0.05$ & $404.85 / 0.15$ & $404.9 / 0^{45}$ & higher Rydberg states \\
\hline IP & 405.5 & 405.05 & $405.0,406.0$ & $404.9^{43}$ & \\
\hline G & 408 & 407.3 & 407.2 & $408,^{44} 408.1^{45}$ & $\sigma^{*}$ \\
\hline
\end{tabular}


Table 8. Energies of C K NEXAFS Spectral Features of Nicotine, Nicotinic Acid, Nicotinamide, and Pyridine

\begin{tabular}{|c|c|c|c|c|c|}
\hline \multirow[b]{2}{*}{ peak } & \multicolumn{3}{|c|}{ resonance energy $(\mathrm{eV})$, present data } & \multicolumn{2}{|c|}{ resonance energy $(\mathrm{eV})$, reference compound } \\
\hline & nicotine & nicotinic acid & nicotinamide & pyridine (literature) & assignment \\
\hline A & 284.84 & 284.89 & 284.89 & $284.9^{45}$ & $\mathrm{C} 2, \mathrm{C} 3 \rightarrow \pi^{*}\left(\mathrm{~b}_{1}\right)^{45}$ \\
\hline B & 285.00 & 285.03 & 285.00 & & vibronic state \\
\hline $\mathrm{C}$ & 285.37 & 285.23 & 285.33 & $285.5^{45}$ & $\mathrm{C} 1 \rightarrow \pi^{*}\left(\mathrm{~b}_{1}\right), \mathrm{C} 2 \rightarrow \pi^{*}\left(\mathrm{a}_{2}\right)^{45}$ \\
\hline $\mathrm{D}$ & 285.50 & 285.36 & 285.48 & & vibronic state \\
\hline $\mathrm{E}$ & 285.83 & 285.81 & 285.88 & $285.8^{45}$ & $\mathrm{C} 1 \rightarrow \pi^{*}\left(\mathrm{a}_{2}\right)^{45}$ \\
\hline $\mathrm{F}$ & 287.14 & & & $287.3^{45}$ & $\mathrm{C} 2, \mathrm{C} 3 \rightarrow \sigma^{*}\left(\mathrm{a}_{1}\right)^{45}$ \\
\hline $\mathrm{F}^{\prime}$ & & 287.59 & & & \\
\hline G & 287.60 & & & & \\
\hline $\mathrm{G}_{1^{\prime}}$ & & 288.04 & & & $\mathrm{C} 1 \rightarrow \pi^{*}(\mathrm{C}=\mathrm{O})$ \\
\hline $\mathrm{G}_{2^{\prime}}$ & & 288.19 & & & \\
\hline $\mathrm{G}_{3^{\prime}}$ & & 288.31 & & & \\
\hline $\mathrm{G}_{4^{\prime}}$ & & 288.49 & & & \\
\hline $\mathrm{G}^{\prime \prime}$ & & & 288.1 & & \\
\hline $\mathrm{H}$ & 288.00 & & & & \\
\hline I & 288.7 & & & & \\
\hline $\mathrm{I}^{\prime \prime}$ & & & 288.75 & & \\
\hline $\mathrm{J}$ & 289.28 & & & & \\
\hline $\mathrm{J}^{\prime}$ & & 289.44 & & & \\
\hline $\mathrm{J}^{\prime \prime}$ & & & 289.34 & & \\
\hline IP, C7 & & 295.07 & 294.14 & & \\
\hline
\end{tabular}

very similar. The most pronounced difference between conformers was predicted to be $210 \mathrm{meV}$ at the $\mathrm{C} 4$ site of nicotinamide, and the experimental spectra favor the trans conformer, which is not consistent with the valence data. All other calculated shifts were too small to be observed in this experiment. This confirms the widely held view that generally rotational isomers display weak core-level spectral changes, unless a stronger interaction, such as intramolecular hydrogen bonds, is involved.

We have measured and assigned the NEXAFS spectra of the three compounds. By comparing with reference compounds and analyzing the term values, we find evidence that the delocalized orbitals of the pyridine ring and the substituent undergo $\pi^{*}-\pi^{*}$ interaction. This leads to shifts in orbital energies and new resonances in NEXAFS for nicotinic acid and nicotinamide. Although these two compounds are isoelectronic, their structures are different, because nicotinic acid is planar and nicotinamide is twisted. This leads to different degrees of orbital mixing.

\section{ASSOCIATED CONTENT}

\section{SI Supporting Information}

The Supporting Information is available free of charge at https://pubs.acs.org/doi/10.1021/acs.jpca.9b11586.

Complete list of vertical ionization energies of nicotine calculated using the OVGF/6-311++G** method; figures showing potential energy scans of nicotine, nicotinic acid, and nicotinamide calculated using the B3LYP/6-311+ $+\mathrm{G}^{* *}$ model; comparison of the charge distributions of the outermost five valence states of trans-a and trans-b nicotine; $\mathrm{O}$ 1s spectra of nicotinic acid and nicotinamide; C 1s spectra of nicotinic acid and nicotinamide (with fitted peaks); N 1s spectra of nicotine, nicotinic acid, and nicotinamide (with fitted peaks) (PDF)

\section{AUTHOR INFORMATION}

\section{Corresponding Authors}

Hanan Sa'adeh - Department of Physics, The University of Jordan, 11942 Amman, Jordan; Elettra Sincrotrone Trieste, 34149 Basovizza, Trieste, Italy; 이 orcid.org/0000-0002-25685507; Email: Hanan.Saadeh@ju.edu.jo

Feng Wang - Centre for Translational Atomaterials and Department of Chemistry and Biotechnology, Swinburne University of Technology, Melbourne, Victoria 3122, Australia; ○ orcid.org/0000-0002-6584-0516; Email: fwang@ swin.edu.au

Authors

Frederick Backler - Centre for Translational Atomaterials and Department of Chemistry and Biotechnology, Swinburne University of Technology, Melbourne, Victoria 3122, Australia

Susanna Piccirillo - Dipartimento di Scienze e Tecnologie Chimiche, Università di Roma "Tor Vergata”, 00133 Rome, Italy; $\odot$ orcid.org/0000-0002-7938-6852

Alessandra Ciavardini - CERIC-ERIC, 34149 Basovizza, Trieste, Italy

Robert Richter - Elettra Sincrotrone Trieste, 34149 Basovizza, Trieste, Italy; ○ orcid.org/0000-0001-8585-626X

Marcello Coreno - ISM-CNR, 34149 Basovizza, Trieste, Italy

Kevin C. Prince - Elettra Sincrotrone Trieste, 34149 Basovizza, Trieste, Italy; Centre for Translational Atomaterials and Department of Chemistry and Biotechnology, Swinburne University of Technology, Melbourne, Victoria 3122, Australia; (1) orcid.org/0000-0002-5416-7354

Complete contact information is available at:

https://pubs.acs.org/10.1021/acs.jpca.9b11586

\section{Author Contributions}

The experiments were performed by H.S., S.P., A.C., R.R., M.C., and K.C.P., and the calculations were carried out by F.B. and F.W. The manuscript was written through contributions of all authors. All authors have given approval to the final version of the manuscript. 


\section{Notes}

The authors declare no competing financial interest.

\section{ACKNOWLEDGMENTS}

The authors thank their colleagues at Elettra for their support and the provision of high-quality synchrotron light. This work was carried out during scientific leave granted to H.S. from the University of Jordan, Amman, Jordan, during the academic year 2018-2019. H.S. acknowledges the TRIL fellowship awarded by the Abdus Salam International Centre for Theoretical Physics (ICTP), Trieste, Italy. F.B. acknowledges the Research Training Program Stipend (RTPS) of the Australian Government. S.P. acknowledges the financial support from the Italian MIUR (PRIN 2010ERFKXL_006).

\section{REFERENCES}

(1) Grabow, J.-U.; Mata, S.; Alonso, J. L.; Peña, I.; Blanco, S.; López, J. C.; Cabezas, C. Rapid Probe of the Nicotine Spectra by HighResolution Rotational Spectroscopy. Phys. Chem. Chem. Phys. 2011, 13, 21063-21069.

(2) Elmore, D. E.; Dougherty, D. A. A Computational Study of Nicotine Conformations in the Gas Phase and in Water. J. Org. Chem. 2000, 65, 742-747.

(3) Takeshima, T.; Fukumoto, R.; Egawa, T.; Konaka, S. Molecular Structure of Nicotine As Studied by Gas Electron Diffraction Combined with Theoretical Calculations. J. Phys. Chem. A 2002, 106, 8734-8740.

(4) Vogelsanger, B.; Brown, R. D.; Godfrey, P. D.; Pierlot, A. P. The Microwave Spectrum of a Vitamin: Nicotinamide. J. Mol. Spectrosc. 1991, 145, 1-11.

(5) Mata, S.; Peña, I.; Cabezas, C.; López, J. C.; Alonso, J. L. A Broadband Fourier-Transform Microwave Spectrometer with Laser Ablation Source: The Rotational Spectrum of Nicotinic Acid. J. Mol. Spectrosc. 2012, 280, 91-96.

(6) Dougherty, D.; Younathan, E. S.; Voll, R.; Abdulnur, S.; McGlynn, S. P. Photoelectron Spectroscopy of Some Biological Molecules. J. Electron Spectrosc. Relat. Phenom. 1978, 13, 379-393.

(7) Opitz, J. Electron-Impact Ionization of Benzoic Acid, Nicotinic Acid and Their n-Butyl Esters: An Approach to Regioselective Proton Affinities Derived from Ionization and Appearance Energy Data. Int. J. Mass. Spectrom. 2007, 265, 1-14.

(8) Farrokhpour, H.; Ghandehari, M. Photoelectron Spectra of Some Important Biological Molecules: Symmetry-Adapted-Cluster Configuration Interaction Study. J. Phys. Chem. B 2013, 117, 6027-6041.

(9) Schnadt, J.; O’Shea, J. N.; Patthey, L.; Schiessling, J.; Krempasky, J.; Shi, M.; Martensson, N.; Bruhwiler, P. Structural Study of Adsorption of Isonicotinic Acid and Related Molecules on Rutile $\mathrm{TiO}_{2}(110)$ II: XPS. Surf. Sci. 2003, 544, 74-86.

(10) Abu-samha, M.; Børve, K. J.; Sæthre, L. J.; Thomas, T. D. Conformational Effects in Inner-Shell Photoelectron Spectroscopy of Ethanol. Phys. Rev. Lett. 2005, 95, No. 103002.

(11) Thomas, T. D.; Sæthre, L. J.; Børve, K. J. Effects of Molecular Conformation on Inner-shell Ionization Energies. Phys. Chem. Chem. Phys. 2007, 9, 719-724.

(12) Holme, A.; Sæthre, L. J.; Børve, K. J.; Thomas, T. D. Carbon 1s Photoelectron Spectroscopy of 1-Pentyne Conformers. J. Mol. Struct. 2009, 920, 387-392.

(13) Holme, A.; Børve, K. J.; Sæthre, L. J.; Thomas, T. D. Conformations and $\mathrm{CH} / \pi$ Interactions in Aliphatic Alkynes and Alkenes. J. Phys. Chem. A 2013, 117, 2007-2019.

(14) Turchini, S.; Catone, D.; Zema, N.; Contini, G.; Prosperi, T.; Decleva, P.; Stener, M.; Rondino, F.; Piccirillo, S.; Prince, K. C.; Speranza, M. Conformational Sensitivity in Photoelectron Circular Dichroism of 3-Methylcyclopentanone. Chem. Phys. Chem. 2013, 14, $1723-1732$.

(15) Islam, S.; Ganesan, A.; Auchettl, R.; Plekan, O.; Acres, R. G.; Wang, F.; Prince, K. C. Electronic Structure and Intramolecular
Interactions in Three Methoxyphenol Isomers. J. Chem. Phys. 2018, 149, No. 134312.

(16) Plekan, O.; Feyer, V.; Richter, R.; Coreno, M.; de Simone, M.; Prince, K. C.; Carravetta, V. Photoemission and the Shape of Amino Acids. Chem. Phys. Lett. 2007, 442, 429-433.

(17) Plekan, O.; Feyer, V.; Richter, R.; Coreno, M.; de Simone, M.; Prince, K. C.; Carravetta, V. Investigation of the Amino Acids Glycine, Proline, and Methionine by Photoemission Spectroscopy. J. Phys. Chem. A 2007, 111, 10998-11005.

(18) Zhang, W.; Carravetta, V.; Plekan, O.; Feyer, V.; Richter, R.; Coreno, M.; Prince, K. C. Electronic Structure of Aromatic Amino Acids Studied by Soft X-ray Spectroscopy. J. Chem. Phys. 2009, 131, No. 035103.

(19) Feyer, V.; Plekan, O.; Kivimäki, A.; Prince, K. C.; Moskovskaya, T. E.; Zaytseva, I. L.; Soshnikov, D.; Trofimov, A. B. Comprehensive Core-Level Study of the Effects of Isomerism, Halogenation, and Methylation on the Tautomeric Equilibrium of Cytosine. J. Phys. Chem. A 2011, 115, 7722-7733.

(20) Maris, A.; Melandri, S.; Evangelisti, L.; Caminati, W.; Giuliano, B. M.; Plekan, O.; Feyer, V.; Richter, R.; Coreno, M.; Prince, K. C. Soft Xray Photoemission Spectroscopy of Selected Neurotransmitters in the Gas Phase. J. Electron Spectrosc. Relat. Phenom. 2012, 185, 244-251.

(21) Ahmed, M.; Wang, F.; Acres, R. G.; Prince, K. C. Structures of Cycloserine and 2-Oxazolidinone Probed by X-ray Photoelectron Spectroscopy: Theory and Experiment. J. Phys. Chem. A 2014, 118, $3645-3654$

(22) Feyer, V.; Plekan, O.; Richter, R.; Coreno, M.; Prince, K. C.; Carravetta, V. Core Level Study of Alanine and Threonine. J. Phys. Chem. A 2008, 112, 7806-7815.

(23) Myrseth, V.; Bozek, J. D.; Kukk, E.; Sæthre, L. J.; Thomas, T. D. Adiabatic and Vertical Carbon 1s Ionization Energies in Representative Small Molecules. J. Electron Spectrosc. Relat. Phenom. 2002, 122, 57-63.

(24) Thomas, T. D.; Shaw, R. W., Jr. Accurate Core Ionization Potentials and Photoelectron Kinetic Energies for Light Elements. J. Electron Spectrosc. Relat. Phenom. 1974, 5, 1081-1094.

(25) Tronc, M.; King, G. C.; Read, F. H. Carbon K-shell Excitation in Small Molecules by High-Resolution Electron Impact. J. Phys. B: At. Mol. Phys. 1979, 12, 137; 1980, 13, 999.

(26) Sodhi, R. N. S.; Brion, C. E. Reference Energies for Inner Shell Electron Energy-Loss Spectroscopy. J. Electron Spectrosc. Relat. Phenom. 1984, 34, 363-372.

(27) Wight, G. R.; Brion, C. E. K-Shell Energy Loss Spectra of $2.5 \mathrm{keV}$ Electrons in $\mathrm{CO}_{2}$ and $\mathrm{N}_{2}$ O. J. Electron Spectrosc. Relat. Phenom. 1974, 3, 191-205.

(28) Cavigliasso, G.; Chong, D. P. Accurate Density-Functional Calculation of Core-Electron Binding Energies by a Total Energy Difference Approach. J. Chem. Phys. 1999, 111, 9485-9492.

(29) Takahata, Y.; Chong, D. P. DFT Calculation of Core-Electron Binding Energies. J. Electron Spectrosc. Relat. Phenom. 2003, 133, 69-76.

(30) Takahata, Y.; Wulfman, C. E.; Chong, D. P. Accurate Calculation of N1s and C1s Core Electron Binding Energies of Substituted Pyridines. Correlation with Basicity and with Hammett Substituent Constants. J. Mol. Struct.: THEOCHEM 2008, 863, 33-38.

(31) Shapley, W. A.; Chong, D. P. PW86-PW91 Density Functional Calculation of Vertical Ionization Potentials: Some Implications for Present-Day Functionals. Int. J. Quantum Chem. 2001, 81, 34-52.

(32) Chong, D. P.; van Lenthe, E.; van Gisbergen, S.; Baerends, E. J. Even-Tempered Slater-Type Orbitals Revisited: From Hydrogen to Krypton. J. Comput. Chem. 2004, 25, 1030-1036.

(33) Te Velde, G.; Bickelhaupt, F. M.; Baerends, E. J.; Fonseca Guerra, C.; Van Gisbergen, S. J. A.; Snijders, J. G.; Ziegler, T. Chemistry with ADF. J. Comput. Chem. 2001, 22, 931-967.

(34) Frisch, M. J.; Trucks, G. W.; Schlegel, H. B.; Scuseria, G. E.; Robb, M. A.; Cheeseman, J. R.; Scalmani, G.; Barone, V.; Mennucci, B.; Petersson, G. A.; et al. Gaussian 09, revision A.02; Gaussian, Inc.: Wallingford, CT, 2009.

(35) Kumar, M.; Yadav, R. A. Experimental IR and Raman Spectra and Quantum Chemical Studies of Molecular Structures, Conformers and 
Vibrational Characteristics of Nicotinic acid and its N-oxide. Spectrochim. Acta, Part A 2011, 79, 1316-1325.

(36) Koczoń, P.; Dobrowolski, J. C. z.; Lewandowski, W.; Mazurek, A. P. Experimental and Theoretical IR and Raman Spectra of Picolinic, Nicotinic and Isonicotinic Acids. J. Mol. Struct. 2003, 655, 89-95.

(37) Lal, A.; Shukla, N.; Singh, V. B.; Singh, D. K. Theoretical and Experimental Studies of Vibrational Spectra of Nicotinic Acid. J. Chem. Pharm. Res. 2016, 8, 136-142.

(38) Thaya Kumari, C. R.; Nageshwari, M.; Ganapathi Raman, R.; Lydia Caroline, M. Crystal Growth, Spectroscopic, DFT Computational and Third Harmonic Generation Studies of Nicotinic Acid. J. Mol. Struct. 2018, 1163, 137-146.

(39) Kumar, M.; Jaiswal, S.; Singh, R.; Srivastav, G.; Singh, P.; Yadav, T. N.; Yadav, R. A. Ab initio Studies of Molecular Structures, Conformers and Vibrational Spectra of Heterocyclic Organics: I. Nicotinamide and its N-oxide. Spectrochim. Acta, Part A 2010, 75, 281292.

(40) Ishii, I.; Hitchcock, A. P. A Quantitative Experimental Study of the Core Excited Electronic States of Formamide, Formic Acid, and Formyl Fluoride. J. Chem. Phys. 1987, 87, 830-839.

(41) Prince, K. C.; Richter, R.; de Simone, M.; Alagia, M.; Coreno, M. Near Edge X-ray Absorption Spectra of Some Small Polyatomic Molecules. J. Phys. Chem. A 2003, 107, 1955-1963.

(42) Jolly, W. L.; Bomben, K. D.; Eyerman, C. J. Core-electron binding energies for gaseous atoms and molecules. At. Data Nucl. Data Tables 1984, 31, 433.

(43) Brown, R. S.; Tse, A. Determination of Circumstances under Which the Correlation of Core Binding Energy and Gas-Phase Basicity or Proton Affinity Breaks Down. J. Am. Chem. Soc. 1980, 102, 52225226.

(44) Horsley, J. A.; Stöhr, J.; Hitchcock, A. P.; Newbury, D. C.; Johnson, A. L.; Sette, F. Resonances in the K Shell Excitation Spectra of Benzene and Pyridine: Gas Phase, Solid, and Chemisorbed States. J. Chem. Phys. 1985, 83, 6099-6107.

(45) Vall-llosera, G.; Gao, B.; Kivimäki, A.; Coreno, M.; Álvarez Ruiz, J.; de Simone, M.; Ågren, H.; Rachlew, E. The C 1s and N 1s Near Edge $\mathrm{X}$-ray Absorption Fine Structure Spectra of Five Azabenzenes in the Gas Phase. J. Chem. Phys. 2008, 128, No. 044316.

(46) Baiardi, A.; Mendolicchio, M.; Barone, V.; Fronzoni, G.; Jimenez, G. A. C.; Stener, M.; Grazioli, C.; de Simone, M.; Coreno, M. Vibrationally Resolved NEXAFS at C and N K-Edges of Pyridine, 2fluoropyridine and 2,6-difluoropyridine: A Combined Experimental and Theoretical Assessment. J. Chem. Phys. 2015, 143, No. 204102.

(47) Newbury, D. C.; Ishii, I.; Hitchcock, A. P. Inner Shell Electron Energy Loss Spectroscopy of Some Heterocyclic Molecules. Can. J. Chem. 1986, 64, 1145-1155.

(48) Plekan, O.; Feyer, V.; Richter, R.; Coreno, M.; de Simone, M.; Prince, K. C.; Carravetta, V. An X-ray Absorption Study of Glycine, Methionine and Proline. J. Electron Spectrosc. Relat. Phenom. 2007, 155, 47-53. 